\title{
Seeking to Belong: How the Words of Internal and External Beneficiaries Influence Performance
}

\section{Citation}

Green, Paul, Francesca Gino, and Bradley R. Staats. "Seeking to Belong: How the Words of Internal and External Beneficiaries Influence Performance." Harvard Business School Working Paper, No. 17-073, February 2017.

\section{Permanent link}

http://nrs.harvard.edu/urn-3:HUL.InstRepos:30838597

\section{Terms of Use}

This article was downloaded from Harvard University's DASH repository, and is made available under the terms and conditions applicable to Open Access Policy Articles, as set forth at http:// nrs.harvard.edu/urn-3:HUL.InstRepos:dash.current.terms-of-use\#OAP

\section{Share Your Story}

The Harvard community has made this article openly available.

Please share how this access benefits you. Submit a story.

Accessibility 


\title{
Seeking to Belong: How the Words of Internal and External Beneficiaries Influence Performance
}

\author{
Paul Green \\ Francesca Gino \\ Bradley R. Staats
}

Working Paper 17-073 


\section{Seeking to Belong: How the Words of Internal and External Beneficiaries Influence Performance}

\section{Paul Green}

Harvard Business School

Francesca Gino

Harvard Business School

Bradley R. Staats

University of North Carolina

Working Paper 17-073 
Running Head: SEEKING TO BELONG AT WORK

\title{
Seeking to Belong:
}

How the Words of Internal and External Beneficiaries Influence Performance

\author{
Paul Green \\ Harvard University \\ pgreen@hbs.edu
}

Francesca Gino

Harvard University

fgino@hbs.edu

Bradley R. Staats

University of North Carolina

Bradley_Staats@,kenan-flagler.unc.edu

Corresponding Author:

Paul Green

Cotting 324

Harvard Business School

Soldiers Field Road

Boston, MA 02163

Phone: 209-675-1319 


\section{Acknowledgements}

We thank Amy Edmondson, Adam Grant, Julia Lee, and Kathleen McGinn for their insightful comments on earlier drafts. We also thank the members of OB Lab at Harvard Business School for their developmental and insightful comments as this research was being developed. We are grateful to Chris Rufer, Ron Caoua and others at Morning Star for their substantial investment of time and attention in this study, without which the work would not have been possible. All remaining errors are our own. 


\begin{abstract}
In this paper, we examine how connecting to beneficiaries of one's work increases performance, and argue that beneficiaries internal to an organization (i.e., one's own colleague) can serve as an important source of motivation, even in jobs that - on the surface - may seem routine and low on potential impact. We suggest that this occurs because words of beneficiaries strengthen one's sense of belongingness, a key driver of human behavior. Employees, in fact, seek to belong —and seek to enhance their sense of belongingness in work settings. We conducted two studies using both field and laboratory data from different populations to investigate the psychological consequences and performance benefits of connecting to beneficiaries of one's work. In a longitudinal field experiment of fruit harvesters, we find that though beneficiary contact with the overall customer did not significantly improve productivity, contact with an internal beneficiary that made connectedness salient yielded a persistent increase in productivity relative to a control group. We validate this effect in the laboratory, and provide evidence that the effect is mediated by an enhanced sense of belongingness.
\end{abstract}

\title{
Keywords
}

Prosocial motivation, belongingness, motivation, job design, field experiment 
"And when Nolan came, the captain said, 'Mr. Nolan, we are all very grateful to you today; you are one of us to-day; you will be named in the despatches.' And then the old man took off his own sword of ceremony, and gave it to Nolan, and made him put it on. The man told me this who saw it. Nolan cried like a baby, and well he might. He had not worn a sword since that infernal day at Fort Adams. But always afterwards, on occasions of ceremony, he wore that quaint old French sword of the Commodore."

-“The Man Without a Country” by Edward Everett Hale

The American short story, "The Man Without a Country”, by Edward Everett Hale, set in the early $19^{\text {th }}$ century, tells the fictional tale of Army lieutenant Philip Nolan (Hale, 1918). Nolan, while testifying at his trial for treason as a result of his friendship with Aaron Burr, renounces his country in a fit of anger, wishing that he "may never hear of the United States again!" The judge, appalled at the outburst, obliges Nolan, sentencing him to a life at sea as a guest on various vessels, to be treated cordially and well-cared for. But, by order of the judge, he is to never set foot in the United States again, and his hosts are never to utter the name of his country while in Nolan's presence. Nolan spends the rest of his life roaming the seas, treated well but often begging others on his host ship to tell him of his country - usually to no avail.

The punishment seems benign at first blush; a life of relative leisure at sea, under the attentive care of an ever-respectful and gracious host, while not ideal, seems a modest sentence for so egregious an act. But the true price of the punishment is conveyed in a single line of the story. The battleship on which Nolan is, at one point, traveling, becomes embroiled in battle. A cannon ball from an enemy ship kills the officer of the gun, and most of the gun's crew. Nolan, who'd been trained in the operation of a cannon, jumps in and rounds up a ragtag group of crewmembers to assist him in operating the guns to great effect. When the battle is over, and they've conquered the enemy ship, the captain —-Nolan's host—by way of gratitude, bequeaths the conquered captain's sword to Nolan. But it's a single phrase - and Nolan's response - that 
conveys the true price of Nolan's misdeeds. The captain, in his statement of gratitude, tells Nolan, "you are one of us to-day." This statement — and the realization that, on all days but today, Nolan is, without exception, not considered one of them says everything that must be said of what it means to be exiled. And Nolan's response - to cry "like a baby"-says everything that must be said about man's desperate need to belong.

It is a need - a deep and fundamental need. Psychology theorists from Freud to Maslow have long postulated the fundamental human need to be socially connected to others (Maslow, 1968). A broad body of empirical literature in psychology and social psychology provides substantial evidence not only that humans have this fundamental need, but also that they are motivated to fulfill this need (Baumeister and Leary, 1995). Although organizations are inherently social institutions - domains in which individuals might, very logically, look to fulfill their drive to belong - our theories of work motivation do not adequately account for this drive, and our interventions designed to increase motivation don't leverage the fulfillment of this need to belong as a mechanism for increasing employee motivation.

Most theories regarding what factors may increase worker motivation, grounded in the job design literature, argue for altering the inherent attributes of jobs through job redesign or job crafting (Hackman and Oldham, 1976, 1980; Morgeson and Campion, 2003; Morgeson and Humphrey, 2008). More recent research identifies the importance of leveraging the social characteristics of work, and finds that interactions with the beneficiaries of one's work can be a motivating experience by influencing workers' perceptions of the impact of their work. But these more relational interventions are universally situated in contexts in which the beneficiary is close, salient and identified (Grant et al., 2007; Grant, 2008a). In fact, this broader literature is motivated by the increase in service work and broader economic trends away from 
manufacturing, and toward functions that involve meeting "the needs of customers and clients" with "information and service" (Grant and Parker, 2009: 318).

Though broader economic trends point to shifts away from manufacturing jobs and toward a more expansive service economy, all contexts are not service oriented. And even in service organizations, many jobs are not customer-facing. For example, an organization that provides mailing services to clients who send out mass mailings is a service organization; but the many employees who work in the warehouse where the printing stock is stored, though they contribute in meaningful ways to the customer experience, are distant from the customer, and the impact on the customer. Most service organizations have similar 'back offices' that complete important functions, but do not interact with customers directly. Making the significance of the worker's job salient helps clarify the social impact of employees' efforts- but because the impact is so distant, and somewhat abstract, doing so may carry little motivational potential.

Our work builds on social psychology research that asserts that the need to belong is a fundamental human drive - a need that humans are motivated to fulfill (Baumeister and Leary, 1995). We build on theory and empirical literature that suggests that individuals behave differently toward those with whom they feel a strong sense of belonging - they're more concerned with their welfare, and behave in ways likely to solidify this social connectedness (M. Leary and Allen, 2010; Batson, Ahmad, and Stocks, 2011). Importantly, we argue, belongingness relationships make workers more sensitive to the needs of others-causing them to be more responsive to those others' desires than they would be to a relatively disconnected beneficiary - a relational feature that activates prosocial motivation to the benefit of others. Most work contexts have multiple beneficiaries: the ultimate beneficiary (i.e. a customer or client), and various internal individuals who depend on others' work in order to adequately carry 
out their own work. Interactions with these internal beneficiaries can, we propose, yield relatively greater increases in motivation than interaction with external beneficiaries, without any changes to the job function itself, because interactions with internal beneficiaries also serve to heighten employees' sense of belongingness. Interactions with internal beneficiaries may be preferable to interaction with external beneficiaries when external beneficiaries are distant, simply because employees feel closer to, and consequently, more apt to devote care and attention to the needs of internal colleagues. We propose that organizations can leverage this drive, creating opportunities through small interventions, for employees to interact with others with whom they have, or seek to have, a belongingness relationship — and in doing so, increase motivation to perform to the benefit of other employees in interdependent functions. We further propose that these interactions with internal beneficiaries will actually lead to higher work motivation than will interactions with external beneficiaries for whom the objective impact of the employee's work is high (relative to the impact on internal beneficiaries).

We test these general hypotheses with a field experiment tracking the performance of 180 fruit harvesting groups over a period of weeks. We find that, in this context, where customers are perceived as distant, the words of customers (external beneficiaries) yield no increase in work performance. But those of internal beneficiaries make belongingness salient, and remind workers of the interdependent nature of the relationship, thus producing a dramatic effect on subsequent performance. In a second study, we use a laboratory experiment to conceptually replicate the performance benefits of internal beneficiaries who make belongingness salient and validate the mechanisms suggested by our field experiment and identified in our arguments.

Our work extends the growing relational job design literature (Morgeson and Campion, 2003; Grant, 2007; Grant and Parker, 2009) —and the expansive work motivation literature, more 
generally (Hackman and Oldham, 1980; Mitchell and Daniels, 2003; Latham and Pinder, 2005) - by showing one important path by which interactions with others can lead to increases in performance, even in job domains where the impact on beneficiaries is distant or abstract. We incorporate insights from social psychology to show that positive words from internal beneficiaries hold a distinct advantage over positive words from external beneficiaries: words from internal beneficiaries are the vehicles by which employees cultivate and maintain their sense of belongingness - a psychological state that can activate powerful prosocial motives to the benefit of these internal beneficiaries. The words of external beneficiaries, though they carry important information about a worker's impact on clients and customers, can do little to directly enhance an employee's sense of belongingness because they don't originate from a belongingness target. We believe this work opens a door to future study of the ways by which relational interactions and the psychological experiences of relationships in organizational settings can influence employee behavior in positive ways.

Our work also contributes to the positive organizational scholarship literature, which has argued for a more nuanced understanding of the nature of relationships at work, and has further suggested that positive relationships can be invigorating and enhance engagement (J. Dutton, Debebe, and Wrzesniewski, 1999; J. E. Dutton and Heaphy, 2003; J. E. Dutton and Ragins, 2007). We extend this theorizing with insights into the ways that individual interactions at work can help shape the nature of employee relational experiences, and the ways in which those relational experiences fulfill employees' sense of social connectedness.

\section{RELATIONAL JOB DESIGN AND SOCIAL IMPACT}

Recent advances in the examination of the motivational potential of job characteristics suggest that interaction with the beneficiaries of one's work can enhance the worker's perception 
of their work's significance, leading to an increase in prosocial motivation to the benefit of those beneficiaries (Grant, 2007; Grant et al., 2007; Grant, 2008a, 2008b). This evidence provides promising insight into the ways that employers can create simple opportunities that activate employees' prosocial motivation, and help find meaning in their work. Grant, et al. (2007: 2) argue that contact with the beneficiaries of one's work can help the employee "become aware of the significance of their tasks," in turn activating the "motivation to have a positive impact on their beneficiaries." This research suggests that interactions with one's beneficiaries, in person or through indirect communications, increase a worker's sense of perceived impact on othersthe "degree to which employees are aware that their actions affect others" (Grant, 2007: 399).

This theoretical observation is grounded in the idea that work is more meaningful to the degree it positively impacts others. The job impact perspective draws on social information processing theory to suggest that interactions with the beneficiaries of one's work help workers see the impact their work has on others (Salancik and Pfeffer, 1978; Zalesny and Ford, 1990). The implication of this view is clear: relational interactions with beneficiaries carry the potential to enhance employees' prosocial motivation, to the degree those relational interactions expose and clarify the real and substantive impact the focal employee's work might have on the beneficiary. Indeed, Grant (2007: 400), presented a theoretical argument suggesting that a worker's perceived impact on beneficiaries is a function of both the objective job impact of that worker's efforts, and the nature of the contact with beneficiaries.

This line of exploration has proven fruitful, spawning a body of research focused on introducing beneficiary contact into jobs as a means of elucidating employees' impact on their clients and customers, allowing the employees to make better sense of (create meaning around) their work, and leading to marked increases in performance. For example, Grant et al. (2007) and 
Grant (2008a) show that beneficiary contact with students who will receive scholarships increases the motivation of fundraisers attempting to secure donations in support of those scholarships. Grant (2008a) shows how stories about people whose lives have been saved by lifeguards help other lifeguards maintain their vigilance while at work and Grant \& Hofmann show how the words of beneficiaries yield greater performance gains than those of inspirational leaders. Finally, Buell and Norton (2011) find that cooks, seeing the person who will eat the food they prepare, works harder to ensure the prepared food is pleasing to the diner. These contexts, though varied, share two important characteristics: first, the beneficiaries are all external (e.g. customers or clients, or people who are otherwise not part of the organization); second, the impact on these beneficiaries is direct and unadulterated.

These contextual factors, though, are not universally characteristic of all jobs-even in service organizations. Many jobs and functions are such that the impact on customers or beneficiaries, even if substantive and meaningful, is distant and muted by various intervening functions. Consider, for example, an assembly line worker installing screws in the assembly of a wire harness for the electrical system of an automobile; clearly the screws are important and vital, but the distinct impact made by this worker on the ultimate driver of the car is distant and abstract — and seems to be a tiny fraction of the driver's prospective overall experience upon receiving the automobile.

The relational job design literature, while opening an important door to enhancing worker motivation through relational interactions, also exposes an important opportunity to expand the core ideas to non-service functions. Relational interactions can certainly serve to illuminate the impact of an employee's work on a customer; but relational interactions also have the potential to aide and enable relationship formation - a factor that, though potentially less important when 
the beneficiary is a customer or group of customers, may have substantive implications on a worker's behavior if the beneficiary is internal - representative of a group to whom the employee desires to belong, and seeks to solidify their membership in. We argue here that relational interactions with beneficiaries who are internal to the organization serve to facilitate a sense of belongingness in employees, a psychological experience that enhances employees' drive to act to the benefit of those internal beneficiaries. This enhanced belongingness can, in turn, bolster employees' prosocial motivation and lead to increases in performance-increases that surpass the increases associated with mere customer contact interventions.

\section{THE MOTIVATIONAL POTENTIAL OF BELONGINGNESS}

The need to belong is a fundamental human psychological need (Weiss, 1973; Shaver and Buhrmester, 1983), that is fulfilled through routine and regular social contact with others (Baumeister and Leary, 1995). The experience of belongingness, then, is a psychological state of feeling that others care about the self and are interested in well-being of the self (Baumeister and Leary, 1995; Reis, Clark, and Holmes, 2004). Importantly, the experience of belongingness is not necessarily a function of the objective nature of relationships, but rather of an individual's perception of the relational other's feelings toward the self; that is, the psychological state of belongingness is orthogonal to relational partners' actual sentiments and feelings toward the self. Thus, belongingness is relationally facilitated in that, not only must others care about the self, but they must express that care through relational interactions (Reis, Clark, and Holmes, 2004). Relational interactions with others provide insight into, and evidence of, others' sentiments toward the self, and fuel (or starve) one's belief that those relational others care about, and are interested in, the self's well-being (Baumeister and Leary, 1995). 
At a basic level, interactions with other can send important cues regarding parties' social connection to each other. For example, Walton and colleagues (2012) found that interactions with relational others that signal seemingly inconsequential shared characteristics such as birthdates or even membership in arbitrary groups, can lead to increases in individuals" sense of connectedness - a phenomenon they refer to as "mere belonging". These interactions draw on research showing that knowledge of even incidental similarity can serve to tighten the relational connections between individuals (Burger et al., 2004; Jones et al., 2004; Jiang et al., 2010).

Social identity research looks to relational interactions as an important means by which individuals construct their identity (Ashforth and Mael, 1989; Walton and Cohen, 2011). Employees, through interactions with relationally important others, develop a sense of the self as a part of a larger social context (Pratt and Ashforth, 2003). Of particular relevance, recent research examining the identity formation of remote workers suggests that extreme isolation can hamper individuals' progress toward constructing a social identity, hindering the remote employees' ability to see the self as a coherent part of the broader organization, and effectively stifling the internalization of organizational motives (Bartel et al., 2007; Bartel, Wrzesniewski, and Wiesenfeld, 2012). This social isolation, and the resultant stifling of social identity formation, tends to reduce individuals' motivation to act to the benefit of other in-group members (e.g. Twenge et al., 2007). Interactions with relational others that strengthen an individual's sense of belongingness enable the formation of a social identity including the relational other, leading to increases in prosocial motivation.

Various interpersonal experiences have been shown to facilitate an even deeper experience of belongingness. For example, interactions that convey regard for the self, empathic understanding, communal connection — such as togetherness or shared group membership 
(McAdams and de St Aubin, 1992), and simply responsiveness - a recognition and acknowledgement by the relational other of the self, of the self's interests and concerns: all contribute to an individual's perception that the relational other cares and is concerned about the self (Baumeister and Leary, 1995; Reis, 2007). Interactions that Mere expressions of otherwise hidden information about the relational other can increase empathic understanding of the other, leading to an increased sense of belongingness on the part of the individual gaining deeper insight into the thoughts and feelings of the relational other (Ickes and Simpson, 2008). Expressions of gratitude (McCullough et al., 2001), and the more general sense that one's actions matter to another person, also serve to strengthen connections, leading to an enhanced sense of belongingness (Keyes, 1998; Grant and Gino, 2010).

When relational interactions at work convey communal connection, interest in and regard for the relational other, gratitude and empathic understanding-interactions that we collectively refer to as positive interactions - they can facilitate increases in experienced belongingness for participants in the interaction - but only if the participants have a clear drive to belong (Hoyle and Crawford, 1994). That is, expressions of gratitude from an external beneficiary are not likely to inspire an enhanced sense of belonging, simply because the employee has no drive or desire to belong to the "customer" group. Internal beneficiaries represent a unique population in that expressions of gratitude from an internal beneficiary—-because that internal beneficiary is part of a group that the employee expressly desires to cultivate and maintain their membership in, can be powerful signals that serve to enhance the employees' sense of belongingness within the group. In short, positive interactions with internal beneficiaries can carry important, and powerful, cues signaling relational closeness between the internal beneficiary focal employee, enhancing the focal employees' sense of belongingness with the internal beneficiary. 


\section{Belongingness and the Motivation to Act to the Benefit of Others}

The experience of belongingness has a powerful effect on experiencers' behavior toward the group with which they feel they belong. The now legendary Robber's Cave study, for example, demonstrated that belongingness can quickly make close friends of recent enemies (Sherif et al., 1961). When boys who'd been previously part of opposing groups were randomly assigned to new groups, the drive to be a part of the in-group (even though the in-group had recently been an enemy group), led to the relatively rapid emergence of cooperative and ingratiating behavior. We are generally motivated to care for those who we perceive care for us - that is, humans seem to have a natural tendency to reciprocate signals of belongingness, motivated in part by a desire to solidify and secure the affection of these relational others, and to in turn extend care and concern for those who we perceive care for us (Gold, Ryckman, and Mosley, 1984; Aron et al., 1989; M. Leary and Allen, 2010). In essence, the experience of belongingness inspires motivation oriented to the benefit of relational others who facilitate the enhanced sense of belongingness.

This reciprocal behavior can be both goal-directed and autonomous. From a goaldirected standpoint, ample evidence suggests that individuals strategically engage in ingratiating behaviors that they believe will enhance their likeability in the eyes of relational others with whom they have, or hope to have, a belongingness relationship - a form of impression management designed to solidify social relationships (Clark et al., 1987; M. Leary, 1995; M. R. Leary and Cox, 2008; M. Leary and Allen, 2010). Acting to the benefit of these relational others is one obvious path to enhancing likeability, and in interdependent work environments, one's work product can be a means of enhancing one's likeability; when a dependent colleague facilitates an employee's experience of belongingness, the experiencing employee may in turn 
respond by creating work product that is more suitable or more closely conforms to the dependent colleague's needs — a behavior motivated by the desire enhance the focal employee's likeability in the eyes of the dependent colleague.

Individuals also engage in behavior designed to enhance others' view of their competence as a means of maintaining others' care for us (e.g. Miller et al., 1996; Thornton et al., 2006; Urdan and Mestas, 2006). Leary and Allen (2010: 42) argue that "a great deal of achievement oriented behavior is enacted in service of interpersonal goals." We view our competence as a means of enhancing our attractiveness to others, and in belongingness relationships, may engage in behaviors designed to signal our competence with the express purpose of solidifying others' acceptance of us. This is particularly true in domains (such as work domains) in which competence is an explicitly valued trait.

Finally, individuals may, given the experience of belongingness, subconsciously engage in behaviors that serve to ingratiate them to relational others. Social identity views of behavior suggest that our relationships help to form our values and interests - that we "learn" our values through interactions with relational others (Aron and McLaughlin-Volpe, 2001; Gardner, Gabriel, and Hochschild, 2002; Aron et al., 2004). Walton and Cohen (2011: 83) argue that, "people acquire their interests in transactions with socially significant others." That is, though we may seek relationships that validate and support our values and beliefs, we also (at least to a degree) are willing to re-form our values, beliefs and interests to conform to those with whom we have close-belongingness - relationships. Indeed, recent research has shown that even minute manipulations designed to increase a participants' sense of social connectedness - e.g. a shared birthday, or shared task-irrelevant preferences - lead to increases in motivation by increasing socially shared goals (Walton et al., 2012). In a work setting, where performance or quality are 
explicit, shared values, facilitating the experience of belongingness may lead to an increase in employees' internalization of these values, shaping their behavior in ways that are more consistent with the organizational values (O’Reilly and Chatman, 1986; Ellemers, De Gilder, and Haslam, 2004).

We argue that belongingness at work is an alternate path to enhancing employees' work motivation. Though traditional conceptions of beneficiary contact are dependent on job contexts high in task significance, and where relational interactions can effectively expose the social value of an employee's work, prosocial motivation triggered by the experience of belongingness is not bounded by this contextual limitation. Employee behavior designed to solidify or maintain others' acceptance of them is not fueled by the employee's perception of the magnitude of their action's impact, but by the degree to which they believe the behavior will enhance their likeability, competence and will confirm their internalized values of performance. That is, motivation to perform, when fueled by experiences of belongingness, is not a function of the degree to which an employee sees their performance as having an impact, but rather by the degree to which they believe their performance will enhance their acceptance by others. In work contexts where performance is explicitly and strongly valued, or in interdependent contexts, where the source of the belongingness is also a dependent colleague (e.g. their performance depends on the work product of the focal employee), the nature of the impact on others may be small — amounting to no more than a matter of convenience — but may still inspire a heightened sense of motivation. For example, when a worker in an auto parts manufacturing facility experiences a heightened sense of belongingness from a downstream colleague, she may respond by increasing the quality of her work as a way of relational maintenance, even if the increased quality amounts to no more than a matter of convenience for the relevant downstream colleague. 


\section{Internal Beneficiaries as Enablers of Belongingness}

We suggest that enabling positive contact between interdependent employees in organizations that leads to an increase in belongingness can lead to substantive increases in performance, driven by the prosocial motivation to maintain and bolster the belongingness relationship. Interactions with internal beneficiaries carry not only information regarding the impact of the employee on the beneficiary, but can also carry words, sentiments and expressions that facilitate the employee's sense of belongingness with this internal and relationally valued other. Because external beneficiaries are, definitionally, not a part of a group to which an employee wishes to belong, contact with external beneficiaries will not carry the same motivational potential of enhanced belongingness. In contexts where impact on external beneficiaries is distant or somewhat abstract, the enhanced sense of belongingness that accompanies interactions with internal beneficiaries carries substantive motivational potentialpotential that exceeds the motivational influence of external beneficiaries' expressions regarding the impact of the employees' work. Therefore, we hypothesize:

Hypothesis 1a: Positive words from internal beneficiaries will lead to increases in motivation relative to employees who are not exposed to the words of internal beneficiaries.

Hypothesis 1b: In contexts where contact with customers is not direct, positive words from internal beneficiaries will lead to greater increases in motivation than will positive words from external beneficiaries, even within the same job.

Hypothesis 2: Increases in perceived sense of belongingness mediates the relationship between the positive words of internal beneficiaries and increased motivation. 


\section{Overview of the Present Research}

We tested our hypotheses in two main studies. The first is a field experiment conducted in a vertically integrated agribusiness company in the Western United States. In this study we tested our primary hypothesis (H1a): that the words of internal beneficiaries motivate employees to greater effort on behalf of those internal beneficiaries. It also tested our secondary hypothesis (H1b): that, in contexts where contact with customers is not direct, activating a sense of belongingness is more motivating than more traditional customer-contact job design interventions. Our second study is a laboratory experiment that provides a conceptual replication of the finding of Study 1 in a different context and tests the mediating effect of belongingness on performance $(\mathrm{H} 2)$. These studies, taken together, provide insight into the power of belongingness to inspire employees to higher levels of motivation.

\section{STUDY 1: METHOD}

\section{Sample and Procedures}

Study 1 was conducted at a vertically integrated agribusiness and food processing company located in the Western United States. The company has three processing facilities located in the region, and farming and vegetable harvesting operations that span a growing region of approximately 31,000 square miles.

Our study focused on employees that harvest tomatoes to be delivered to the companies' processing facilities. The harvester driver is responsible for driving the harvester through the field being harvested, altering settings and speed to ensure all tomatoes are extracted from the field, and that as little foreign material (weeds, vines, rocks, etc...) as possible is extracted. In addition, there are tractor drivers who each pull a set of empty trailers alongside the harvester that the harvester gradually fills with tomatoes. Filled trailers are picked up by a trucking 
company and new, empty trailers dropped off for refilling. The harvesting process-e.g. speed and quality — are driven entirely by the harvester operator, which we henceforth will refer to as the "harvester". The harvesting operation is a 24-hour per day, 7 day per week operation during the harvest season, which lasts about 110 days over the course of each summer. Employees work 12-hour shifts, and harvester and tractor drivers work together from day-to-day, except for days off, when a rotating employee covers the absent employee's shift. Employees rarely interact with other employees - and when they do have interpersonal interaction, it is usually with only one or two other colleagues (e.g. the tractor drivers working alongside a harvester driver), and only during breaks.

Harvesters are generally dispatched directly to the field where they will be harvesting on a particular day, and consequently, harvesting employees rarely (if ever) visit the processing facility that the fruits of their labor will supply. In fact, because the harvesting area is so geographically large, many of the employees will be provided with a hotel room or apartmentin many cases, up to 100 miles away from the processing facility - for the duration of the harvest, and may not ever visit the processing facility. The harvest region spans approximately 400 miles, North to South, and between 50 and 175 miles, East to West, covering over 31,000 square miles (see Figure 1). The everyday nature of these employees' work context is such that, we believe, they are likely to feel a degree of alienation - that is, they are likely to feel a vivid need to belong.

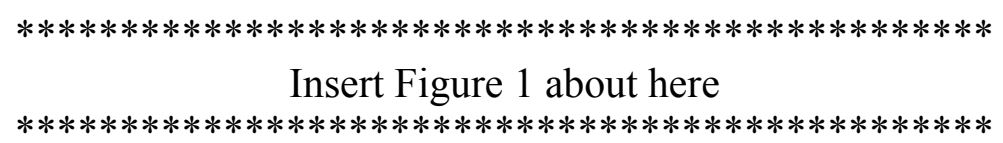

These circumstances provide an excellent context for examining the motivational effects of interventions designed to inspire a sense of belongingness, and in turn, the motivation to impact others. Employees working in this environment are both physically and contextually 
isolated, and rarely (or never) interact with others from within the organization. They work in an isolated environment, far removed from other participants in a much larger overall process, and have very little insight into how their work either fits into a larger process or impacts either an internal or end customer. Importantly, this context is such that, although workers might identify with the organization as a whole, they might suffer from a sense of isolation given their routine detachment from the core organization, and almost certainly suffer from a general belief that others within the others don't care about them —a dearth of belongingness brought on by minimal interactions with others from within the organization.

Experimental manipulation. We tested our primary hypothesis with a field experiment in which we randomly assigned 180 harvesters to one of three conditions: (1) control, (2) internal beneficiary, and (3) external beneficiary. We first compiled a list of all harvesters, randomized the order of this list, and then, for each harvester on the list, drew a slip of paper from a hat to determine that harvester's condition assignment. Although harvesters work in remote locations, they sometimes work in the same geographic area as other harvesters-particularly when harvesting large farms that support two or three harvesters operating concurrently. We identified harvesters that were working in a "grouping", and during our randomization process, when we arrived at a harvester on the list that was part of a broader grouping, we selected a condition from the hat for each harvester in that group (without replacement), such that each grouping included one harvester assigned to each condition. The company allowed us 3 days to complete the intervention, and because of the geographic dispersion of the harvesters, we knew we would not be able to cover all harvesters. Our strategy was to work our way down the randomized list until our window of opportunity closed. 
Harvesters assigned to the internal and external beneficiary groups were invited to complete a brief survey, and then received the treatments described below, while harvesters assigned to the control group were simply invited to complete a brief survey. For purposes of analysis, we test our hypotheses by first including all harvesters that remained (after our intervention window closed) in our control condition, and separately, with only the employee population in the control group who actually completed a survey. Our final sample consisted of 30 harvesters in the internal beneficiary condition; 38 harvesters in the external beneficiary condition; and 112 harvesters in the full control condition, and 32 harvesters in the reduced (survey completer-only) control condition. The full control condition is comprised of (a) all harvesters that were assigned to the control condition as part of our "random draw" condition assignment; and (b) those harvesters that had not received an intervention at the end of our threeday intervention window.

Participants in the internal beneficiary condition viewed a short ( 3 minute) video designed to inspire a sense of belongingness with the internal beneficiaries. The video consisted of a person who could speak knowledgeably about the entire company, who represented the processing facility, but who the harvesting employees were unlikely to know (or know of) delivering a brief monologue. The speaker in this video used the term "we" and "us" frequently, specifically reinforcing the fact that "we are all part of the same company", while making a broader point about how the harvesters' work affected the employees working in the factory by explicitly describing the benefits of harvesting productivity and quality to other internal stakeholders (specifically the processing facilities). This manipulation was a conceptual variant and extension of past studies of exploring the affect of the words of beneficiaries on workers' 
performance (e.g. Grant and Gino, 2010). The speaker was not given a script, but was asked to briefly address the key topics, and was coached prior to creating the video.

The External Beneficiary video was designed to convey the impact of the harvesters' work on customers, in line with traditional manipulations designed to influence workers' perceived impact on beneficiaries. This video began with the same internal processing facility employee speaking for 3 minutes. The employee described the overall company-describing briefly the various components of the integrated business (e.g. a trucking company, three fruit processing facilities, etc...), the end products that they produce, and the overall scale of the business (e.g. "Our company produces almost half of all of the tomatoes processed for the U.S. markets"). This portion of the video set up the main speaker in the video-a representative of one of the company's largest customers (a large consumer branded food company), by describing how the harvesting operation was connected to the customer through the overall process.

The customer representative portion of the video spanned approximately 5 minutes. The customer representative discussed their branded products (all recognizable consumer brands), including visualizations of the many products that the harvested tomatoes would ultimately be incorporated into, and then went on to discuss how important the harvesting operation was to them as a customer, and specifically, how quality and consistent productivity in the harvesting operation flowed through to the end-product quality and consistency. The customer representative closed by thanking the harvesters for the work they were doing. This intervention was designed to, given the context, make salient the ways in which the harvesters' work positively impacts the company's customers, and to make evident the scope of that impact. This manipulation was conceptually consistent with similar work exploring the social characteristics of work (Grant et al., 2007; Grant, 2008c; Grant and Gino, 2010). 


\section{Empirical Strategy}

The firm captures daily productivity and quality data, by harvester, for all harvesters over the course of the entire harvest period (approximately 18 weeks). Each record includes date, harvester ID, productivity data, hours worked, shift information, weather information, a grower indicator and quality data. Productivity data was measured as tons of tomatoes harvested per operating hour — calculated by dividing the tons harvested by a harvester during the shift by the number of hours the harvester operated that shift. The grower indicator is a unique ID for the farmer whose crop the harvesters are harvesting. Farmers have varying farming practiceswhich can influence the yield in the field (and, to a slight degree) the overall productivity of the harvesters working in the fields. We coded each record with a dummy variable indicating whether the shift was pre (0) or post (1) intervention. The number of shifts for which we captured data following the intervention varied by harvester, as the harvest season end is dictated

primarily by the onset of Fall temperatures and rain, which varies across the state. Consequently, the number of post-intervention records collected varied by harvester - from 1 to 26, with a mean of 13.06 .

We tested our hypothesis using an ordinary least squares (OLS) differences-indifferences specification to estimate the following model (model 1):

$$
\mathrm{PROD}_{i, j}=\beta_{1}+\mathrm{POST}_{i, j}+\mathrm{POST}_{i, j} \times \operatorname{INTERNAL}_{i}+\mathrm{POST}_{i, j} \times \mathrm{EXTERNAL}_{i}+\text { Controls } \varepsilon_{i, j}
$$

Where $P R O D_{i, j}$ is the total productivity for harvester $(i)$ on a specific day $(j) ; P O S T_{i, j}$ is an indicator that takes on a value of 1 if the record is after the intervention date for that particular harvester. Our coefficients of interest are two interaction terms, estimating the pre to postintervention change in performance for those in the internal, and external, beneficiary conditions, relative to the pre to post-intervenion change in productivity for those in the control condition 
(our omitted category). POST $i, j X I N T E R N A L_{i, j}$ is a dummy variable that takes on a value of 1 if the record is after the intervention date for that particular harvester, and the harvester received the internal beneficiary intervention; and where POST $T_{i, j} x E X T E R N A L_{i}$ is a dummy variable that takes on a value of 1 if the record is after the intervention date for that particular harvester, and the harvester received the external beneficiary intervention; and Controls is a set of control variables.

Controls. We control for quality as, in our field context, fruit quality can have a substantive impact on employees' ability to effectively and efficiently harvest the fruit. We control for cumulative tons harvested by the employee since the beginning of the season, and the square of cumulative tons harvested since the beginning of the season, to account for learning over the course of the season. We also control for shift-level characteristics: a binary indicator for night shifts, as productivity notoriously drops at night (as harvesters and tractors must drive slower in fields that are not well lit); and a temperature indicator, with temperature data taken from US Meteorological Service weather stations in the general field vicinity, as hotter temperatures lead to more rapid exhaustion (temperatures can easily reach well over 100 degrees F in the field). Finally, we control for consecutive days worked by the primary harvester driver, and the percent of the shift during which the harvester was not operating (as harvesting machines sometimes break down, or experience other downtime not accounted for by our calculated dependent variable).

Empirical model. Our specification is a dual fixed-effects model, with harvester operator fixed effects, as well as grower fixed-effects (to account for differences in grower practices leading to differing yields in the field - a factor that can influence worker productivity). We cluster standard errors at the harvester level to correct for standard errors correlated at the 
individual level (Huber, 1967; White, 1982). We also estimated a version of the model without grower fixed-effects as a robustness check; the results do not change substantively, and eliminating the grower fixed-effects does not substantively alter the statistical significance for any of our covariates of interest.

\section{STUDY 1: RESULTS AND DISCUSSION}

Model 2 in Table 1 provides OLS coefficients for our primary specification, and generally supports our first two hypotheses. Our coefficients of interest are the estimated coefficients for POST $i, j X I N T E R N A L_{i, j}$ and POST $T_{i, j} X E X T E R N A L i$. In our differences-indifferences model, these two coefficients estimate the difference in the change in pre and postintervention productivity for each of the experimental populations, relative to the change, pre-topost intervention, for the control population (the omitted category).

We find support for our Hypothesis 1a, which predicted an increase in performance for those who experienced the positive words of internal beneficiaries, relative to those who did not have any form of beneficiary contact. The coefficient on POST $i, j x I N T E R N A L_{i, j}$ of $1.983(p=$ 0.012) suggests that, controlling for quality and cumulative experience, as well as shift characteristics, the difference in pre and post-intervention productivity for groups in the internal beneficiary condition was a statistically significant 1.983 tons per hour greater than the pre-topost-intervention change for groups in the control condition. Importantly, this translates to an approximately $7 \%$ increase in tons harvested, per hour, relative to the control condition.

We find no statistically significant difference between the control condition and the external condition. The coefficient of 0.305 on the POST $i, j x E X T E R N A L_{i}$ interaction is not statistically significant $(\mathrm{p}=0.666)$, suggesting that the change in performance, pre to postintervention, for those harvesters that watched the external beneficiary video, did not differ 
significantly from the change in performance for those in the control condition. Our Hypothesis $1 \mathrm{~b}$ predicted that those in the internal beneficiary condition would perform at a higher postintervention level than those in the external beneficiary condition. To test this hypothesis, we conducted a post-estimation incremental F-test to test for a difference between these two experimental conditions $\left(\mathrm{H}_{0}\right.$ : Internal $=$ External $)$. As predicted, the results of our incremental Ftest $(p=0.0685)$ allow us to reject the null hypothesis of no significant difference between POST $_{i, j} x I N T E R N A L_{i, j}$ and POST $i, j X E X T E R N A L_{i}$ at a $90 \%$ confidence level. These results, consistent with our Hypothesis $1 \mathrm{~b}$, suggest that the change in pre to post-intervention performance for those in the internal beneficiary group was significantly greater than the change in pre to post-intervention performance for those in the external beneficiary group at $p<0.10$.

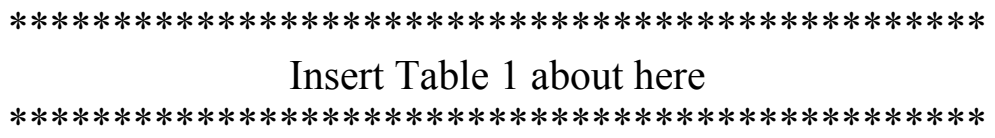

Robustness Check. Model 3 in Table 1 includes results from the same regression, excluding employees from the Control group who did not receive any form of intervention (e.g. did not complete the survey completed by those in our Control condition). Recall that our primary model (Model 2) incorporated all harvesters who remained after our intervention window passed into the Control group; Model 3 excludes those remaining employees from our analysis.

Our key findings are robust to the exclusion of these additional harvesters. The coefficient on POST $i, j X I N T E R N A L_{i, j}$ of $1.974(p=0.020)$ is consistent in magnitude, direction and statistical significance with our primary model. The coefficient of 0.310 on the $P{ } T_{i, j} x E X T E R N A L_{i}$ interaction is still not statistically significant $(\mathrm{p}=0.670)$, and the results $(p$ 
$=0.0585)$ of our post-estimation incremental F-test, testing for a difference between the two experimental conditions, remains statistically significant at $p<0.10$.

\section{Discussion}

These results support our two primary hypotheses (H1a and H1b). First, we find that when employees work in jobs in which the customer impact is distant and abstract, the words of the customer don't have a significant impact on worker's performance. We find, though, that the words of others within the organization — words that make salient the fact that both the workers and the beneficiaries are in this together, that they are relationally connected to each other in important and meaningful ways - lead to significant, and lasting, improvements in employee performance when coupled with signals that the focal employees' performance can be helpful to the internal beneficiary, even in relatively small ways.

We additionally find that, at a 0.10 level of significance, the improvement in postintervention performance for groups in the internal beneficiary condition was higher than the improvement in post-intervention performance for those in the external beneficiary condition. This provides moderate support for our Hypothesis $1 \mathrm{~b}$, suggesting an important distinction in the minds of employees between internal beneficiaries and external beneficiaries - $a$ benefit that we attribute to an enhanced sense of belongingness (Hypothesis 2).

Our field context, though, does not provide us with the opportunity to test Hypothesis 2. Further, the impact on the external beneficiaries in our field context is qualitatively different in nature than the impact on the internal beneficiaries. To bolster our field evidence that the words of internal beneficiaries carry more motivational potential than the words of external beneficiaries, we turn to the laboratory—where we can validate our hypothesized mechanism, and also eliminate qualitative differences in impact between internal and external beneficiaries.. 


\section{STUDY 2: METHOD}

We predicted, with our Hypothesis 2, that the words of internal beneficiaries would enhance workers' sense of belongingness, and that this enhanced sense of belongingness would mediate the relationship between internal beneficiary contact and motivation. We test this hypothesis directly in our second study.

\section{Sample and Procedure}

We recruited 156 undergraduate and graduate students (40\% male; mean age $=22.88$, s.d.=3.47) from a private university in the Northeastern United States to participate in this study (which lasted two hours) in exchange for $\$ 35$.

We randomly assigned participants to one of three between-subjects conditions: control, internal beneficiary and external beneficiary. Participants were informed that they would spend the next two hours "working as part of our research team" (similar to the procedure used in Cable, Gino \& Staats, (2013) to simulate employment relationships in the context of a laboratory), and that, during that time, they would work on a number of research related tasksincluding entering data from a recent study, problem solving and idea generation tasks that are often part of the early research process.

Participants in all conditions then read a short description of the research group (referred to as "lab"), the type of research conducted in the lab, and specifying that the lab is comprised of doctoral students and professors from various programs and disciplines. Participants in the Internal Beneficiary (External Beneficiary) condition then read an additional body of text:

The researchers working in the lab, whether they are doctoral students, professors or research assistants, have a common goal: develops scientific insights and, whenever possible, evaluates their impact on decision making in organizations and the broader society.

In order for you to get a better sense of the research conducted in the lab, in the 
next few screens you are going to read three letters written by Doctoral Students WHO ARE MEMBERS OF THE THIS LAB (AT OTHER SCHOOLS). These letters talk about how the work done by research assistants in the [NAME OF THE LAB] lab (like YOU today) has helped them in their work.

Please read them carefully.

Participants in the two experimental conditions then read a series of three letters written by members of the lab or doctoral students at other schools, all of which benefitted from the research conducted in the lab (since it informed their work). Each letter explained the type of research conducted by the writer, and how the work done in the lab helped to facilitate that research, and closed with an expression of gratitude for the work the lab participants were doing (see Appendix B for an example of the letters). We reached out to six $\mathrm{PhD}$ students for the internal beneficiary condition and six for the external beneficiary condition, and then carefully selected letters that were conceptually similar to each other to ensure the primary difference between the internal condition letters and the external condition letters was whether the letter writer was from the same university. We used actual letters (rather than made-up ones) as we wanted to not involve deception in our study. A primary goal of this study was to ensure we only manipulated the internal/external nature of the beneficiary; thus, it was important that all letters were similar in nature, and carried the same general messages, whether from an external beneficiary or internal beneficiary. We expected that the communal signals in the internal condition letters (e.g. statements about mutual membership in the lab), combined with the expressions of gratitude, would engender a sense of belongingness for those participants in the internal beneficiary condition, but not for those in the external condition, nor the control condition. Such sense of belongingness would then serve as the mediating mechanism explaining the greater performance we expected to observe in the internal beneficiary than in the external beneficiary or control conditions. 


\section{Measures}

After reading these letters, each participant completed a series of items to measure perceived belongingness (our proposed mediator) and psychological motivation as manipulation checks. We measured belongingness using six items $(\alpha=.94)$, such as "I feel like I am already a part of the research team" and "I feel close to the research team and its members", using a 7point scale (from $1=$ not at all, to $7=$ very much). We measured psychological motivation using six items $(\alpha=.95)$, such as “I feel motivated to work very hard on the various tasks of today's session", "I am eager to get started," and "I will put effort into the various tasks," using a 7-point scale (from $1=$ not at all, to $7=$ very much).

Participants were then directed to begin a series of tasks. They first were asked to enter data from a series of paper documents collected in a prior study. Each participant received a bundle of documents with these data, and were given 30 minutes to enter the data. When the 30 minutes had elapsed, the computer system automatically informed them it was time to move on to the second task. We used performance on this data entry task (in terms of number of entries participants completed within the time they were allotted) as our primary dependent measure.

Then, participants completed a few other tasks where we could not measure differences in performance (as everybody was asked to complete the same quantity and quality of work), but that consisted of materials research assistants often generate or work on as part of their job in the lab. Specifically, participants first engaged in a task in which they were asked to create humorous captions each for five distinct images. Participants then moved onto a task where they were asked to come up with 20 different questions, of varying difficulty, that would be used in future studies. Next, participants were asked to generate five distinct series of numbers that could be used in future studies that utilize the "matrix" problem (in which 2 out of 12 numbers 
add up to 10.00). Finally, participants were asked to write two essays that would be used in future studies, in which future study participants would read and answer questions about them.

\section{STUDY 2: RESULTS AND DISCUSSION}

Table 2 reports the summary statistics of the main variables assessed in the study. Means and standard deviations by condition for our focal variables appear in Table 3.

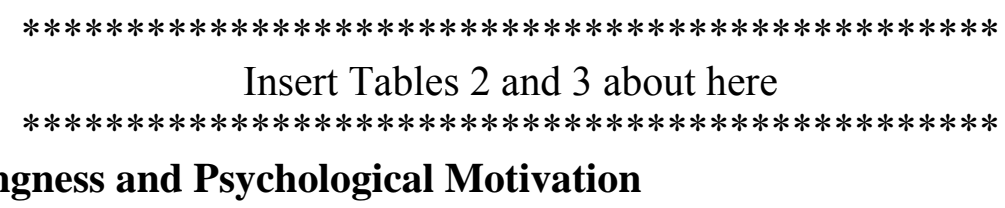

\section{Sense of Belongingness and Psychological Motivation}

We first examined whether participants' sense of belongingness varied across conditions, and found that this was in fact the case $(F(2,153)=21.50, p<.001)$. Participants reported experiencing higher levels of belongingness in the internal beneficiary condition than in both the external beneficiary condition $(p<.001)$ and the control condition $(p=.002)$. We note that sense of belongingness was higher in the external beneficiary condition than in the control condition $(p$ $=.001)$. In addition, participants' motivation varied by condition $(F(2,153)=2.58, p=.079)$. Specifically, participants in the internal beneficiary condition reported greater motivation than did participants in both the external beneficiary condition $(p=.05)$ and in the control condition $(p=.05)$. Together, these results indicate that our manipulation affected our proposed mediator as well as their psychological motivation.

\section{Performance Effects}

As shown in Table 4, as compared to participants in both the external beneficiary condition $(p=.003)$ and the control condition $(p=.016)$, participants in the internal beneficiary condition completed a higher number of entries in the data entry task $(F(2,153)=5.02, p=$ .008), suggesting greater levels of performance. We note that task performance did not differ in the external beneficiary and control conditions $(p=.56)$. 


\section{Mediation Analyses}

Next, we tested whether sense of belongingness mediated the relationship between the positive words received by an internal beneficiary (versus those received by an external beneficiary or the control condition) and task performance. We conducted regression analyses that included an indicator for our internal beneficiary condition and an indicator for our external beneficiary condition.

When both our indicator for the internal beneficiary condition and sense of belongingness were entered into a regression model predicting performance, the indicator for the internal beneficiary condition was no longer significant $(B=1.90, S E B=1.63 ; t=1.17, p=.25)$, whereas sense of belongingness significantly predicted task performance $(B=.93, S E B=.44 ; t$ $=2.14, p=.034$ ). The Preacher and Hayes (2004) bootstrapping technique (with 10,000 iterations) produced a 95\% bias-corrected confidence interval for the indirect effect that excluded zero (.21 to 3.56), thus suggesting a significant indirect effect.

\section{Discussion}

Taken together, these results replicate the findings of Study 1 in a controlled, laboratory environment, and provide support for Hypotheses 1a and 1b, and 2. Notably, they also provide evidence that the psychological mechanism that explain why positive words of beneficiaries lead to greater levels of performance: a heightened sense of belongingness.

\section{GENERAL DISCUSSION}

Organizations, in an effort to maximize employee performance, seek to create motivating environments - environments that yield high levels of employee energy toward organizationally beneficial ends (Mitchell and Daniels, 2003). Recent advances in the realm of social motivation have shown that contact with the beneficiaries' of one's work can make the impact of the 
employee's effort salient, leading to increases in prosocial motivation (Grant and Parker, 2009).

But contact with one's customers is often impractical. More importantly, in many work contexts, the impact of one's efforts on the beneficiary is distant and abstract, thus likely failing to provide the motivational boost needed to persist in one's work. With evidence from a field experiment and a lab experiment, we show that interactions with internal beneficiaries carry the potential for dramatically increasing motivation, and performance, by fulfilling employees' sense of belongingness. We show that the words of internal beneficiaries can enhance employees' sense of relational connectedness in ways that the words of external beneficiaries cannot, and that in contexts where customers are distant and the nature of an employee's impact on those beneficiaries is abstract, organizations may be well suited to create opportunities for positive interactions between workers and the internal colleagues who benefit from their work.

\section{Theoretical Contributions}

This work contributes to the growing body of literature examining relational mechanisms for increasing worker motivation. Most research in this domain has focused on impact as the primary mechanism for enhancing employee motivation to the benefit of others. Our work examines an alternate psychological experience: a worker's sense of belongingness — of relational connectedness — as a source of prosocial motivation yielding important work outcomes. Though an extensive body of social psychology research suggests that we treat others differentially, giving preferential treatment to those with whom we belong (and Batson and Powell, 2003; e.g. Batson et al., 2008; Batson, Ahmad, and Stocks, 2011), little organizational research, to this point, has explored the ways in which organizations can design jobs to facilitate the relational experience of belongingness. We hope this research will spawn an increased interest in understanding the ways that organizational contexts can enable (or hinder) the 
formation of meaningful relationships at work, and how those contexts influence the nature of those relationships.

Additionally, we provide evidence of the way in which even minimal interactions can facilitate employees' sense of belongingness. We acknowledge that all contexts are, perhaps, not as extreme as our field context, and thus minimal interventions are likely to have varying effects across a variety of contexts. But this work illuminates the importance of employee interactions at work on employees' sense of belongingness. Given the important psychological and performance benefits associated with enhanced belongingness, we hope that our work inspires further exploration into the nuances of interpersonal interactions at work - particularly focused on the ways that even routine and seemingly inconsequential interactions at work have markedly influence employees' sense of social wellbeing and motivation.

Our research also contributes to the field of Positive Organizational Scholarship (POS). The POS literature provides ample theoretical support for the importance of employee interpersonal relationships in work contexts. Dutton and Heaphy (2003) suggest that High Quality Connections at work can lead to organizational value by facilitating the exchange of valuable resources (analogous to theories of social capital); by facilitating individual growth and development; and by enabling meaning formation at work. Our work suggests an additional route through which deep and meaningful connectedness with others at work can lead to positive organizational outcomes: the increased capacity and drive to care for, and benefit, those who are the source of the positive experience of belongingness. In interdependent work contexts, the enhanced drive to care for others who are the source of our sense of belongingness can yield organizational benefits. 
Finally, we propose an alternate view of the motivational potential of belongingness in work settings, thus contributing to existing research on belongingness. Most historical research examining an employees' sense of belongingness at work tends to view belongingness as an overarching emotional state that shifts an employee's motivation toward the work associated with the job context along a continuum toward a more internalized form of regulation. Selfdetermination theory, specifically, proposes that when individuals have fulfilled three distinct psychological needs (autonomy, competence and relatedness), they will tend to internalize the motivation toward the task at hand (Deci et al., 2001; Baard, Deci, and Ryan, 2004; Gagné and Deci, 2005). The broader logic of self-determination theory suggests, then, that because individuals have fulfilled these critical psychological needs within their work context, and have thus internalized the motivation toward the work (that is, the motivation for the work has moved along a spectrum from purely extrinsic to an internalized — more self-directed—-form of motivation), they are likely to exert greater effort and persistence. This theory imposes some important conditions, though, on the practical potential of belongingness (or in the lexicon of self-determination theory, relatedness). Gagne and Deci (Gagné and Deci, 2005), in their theoretical description of self-determination theory, argue that, "work climates that promote satisfaction of the three basic psychological needs...will, in turn, yield the important work outcomes of (1) persistence and maintained behavior change; (2) effective performance, particularly on tasks requiring creativity, cognitive flexibility and conceptual understanding..."(emphasis added) (Gagné and Deci, 2005).

But this characterization of the effects of belongingness limits the applicability of this body of work to contexts that fulfill all three psychological needs (autonomy, competence and relatedness), and that are creative and conceptual in nature - in our estimation, an unnecessarily 
limiting conception of the motivating potential of belongingness. We argue for, and show, an alternate path to experiencing the benefits of belongingness - one that does not require a sensitive set of contextual conditions be met in order to activate the motivational benefits. Belongingness activates motivation to the benefit of those who are the source of an individual's sense of belongingness. This motivation to internal beneficiaries' benefit is not contingent on other contextual factors or the fulfillment of the basic needs of autonomy or competence. Perhaps more importantly, the motivational benefits are not a reflection of an employee's internalization of the work, but are simply the product of the employee's desire to act to the benefit of others within the workplace.

\section{Strengths, Limitations and Future Research}

Our investigation offers a number of strengths. First, we present experimental field evidence of the performance benefits associated with enhancing employees' sense of belongingness at work. A field experiment is one of the strongest methods of maximizing the dual desiderata of internal validity and generalizability (Shadish, Cook, and Campbell, 2002). The random assignment to experimental conditions allows us to make causal inferences about the motivational potential of two distinct types of beneficiary interactions; the behavioral nature of our dependent variable allows us to avoid various pitfalls associated with self-reported data. We then augmented our field findings with a laboratory study to further increase internal validity by confirming our hypothesized mechanism.

Our study is not without limitation, though. Our field site is a unique context in the sense that employees spend much of their working day in a state of relative isolation, likely leading to a relatively extreme lack of belongingness. We are under no illusion that a simple video intervention would have as dramatic a performance effect in contexts where employees are as 
belongingness-starved. However, though our intervention was simple and brief, it's worth noting that, even in contexts where employees have more regular interaction with other employees, work interactions often are very stylized. That is, the work context does not necessarily naturally facilitate the formation of strong belongingness bonds; we note that, as conceptualized by Baumeister and Leary (1995), a sense of belongingness is the product of interaction and the relationally facilitated sense of affective care and concern. Routine interactions with others at work, without a general sense that the relational others appreciate and care for the self, may lead to an equally extreme dearth of belongingness. Future research could explore the interactive nature of belongingness at work settings in hopes of better understanding how to facilitate belongingness across a wide variety of work contexts.

There are a number of boundary conditions surrounding our main arguments that future research could test. Our focus in both the field and laboratory study was on social connections at work U.S. contexts characterized by an individualist culture, where the need to belong may be stronger than in organizations and environments outside of the U.S. The fact that workers in the field setting in Study 1 are primarily people born outside of the U.S. gives us some confidence that the relationships we identified are robust.

Nonetheless, it will be useful for future research to examine our hypotheses in other contexts. For example, it is interesting to consider the effects of interventions that increase one's sense of belongingness by relying on connections with colleagues in jobs where rotations or other changes in the organizational members involved in the work occur on a frequent basis. In settings where this is the case, it may be even more important for individuals to feel connected to others, in order for them to stay motivated in their work.

Next, in our studies we focused on jobs that involved little task interdependence. This is 
useful in that it helps rule out possible alternative explanations for the results that have to do with the type of coordination and information sharing needed in those contexts in order to execute the work. However, it is possible that when the job requires more task interdependence, there is a lower experienced need for belonging as interactions with other organizational members occur more frequently -serving as a source of relational connections. It would be useful for future research to focus on employees who work more or less interdependently to measure the extent to which sense of belongingness and its potential performance benefits vary. Future investigations of these and related questions would further our understanding of how connecting to internal beneficiaries of one's work affects employees' experiences and attitudes towards their jobs, as well as their performance.

In our two studies, we focused on the effects of positive words of internal and external beneficiaries on motivation and performance. Other organizationally important variables may be affected by the same intervention, including retention, voice or other organizational citizenships behaviors. Future research could examine whether the positive words of internal beneficiaries also produce benefits for employees in terms of outcomes that go beyond those we examined in this paper.

\section{Conclusion}

Employees seek to fulfill a main psychological drive we all share as human beings: the need to belong. Thus, they seek to enhance their sense of belongingness in work settings. In this paper, we suggested that positive words from beneficiaries internal to an organization (i.e., one's own colleague) serve as an important source of motivation, as they strengthen one's sense of belongingness. We found support for our main arguments in two studies using both field and 
laboratory data from different populations, suggesting that there are both psychological and performance benefits of connecting to beneficiaries of one's work. 


\section{Appendix A}

Transcript of videos used in our experimental manipulation, Study 1

$\underline{\text { Internal Beneficiary Video }}$

Hi my name is [Employee Name].

I have been with [Company Name] for six years working in business development here at the factory. I would like to talk to you today about efficiency and quality and how the two relate to your role.

First and foremost there is obviously a big push in our mission-in everything that we do--to be efficient. However, there is also assumption that quality comes along with this. If we fail on quality or have issues on quality in the long run we are actually less efficient.

The reason efficiency and quality are both important by way of the harvesting group starts with the tomatoes coming into the factory. It is in our Mission is to be the most cost effective, environmentally responsible producer of tomato products. When it comes to our facilities, the more efficient that we can harvest and bring fruit in, the easier it is on the factory over all. What this does it allow us to operate quickly and more effectively by moving product from fresh fruit to the bin or the finish good, which goes to the customer.

We are all one company and it all starts with you. When the fruit comes in and when you are doing your work as efficiently as you can, and we still get the best quality loads coming in as possible overall, we all benefit.

So when sales grow and the marketing efforts can increase and we feel confident that we can export more pounds, that allows for you and us to all come back every year, season after season, and grow.

In closing just remember that the more efficient we can be as a company, which means quality-of course quality is always included--when it comes to efficiency the more efficient we can be as an enterprise we all benefit.

Thanks for your time

\section{$\underline{\text { External Beneficiary Video }}$}

Hi my name is [Employee Name]. I have been with [Company name] for six years in business development here at the factory.

As you all are aware, your first and core mission is to harvest tomatoes. So you may or may not know about the process that actually happens further down the line

The tomatoes that you're harvesting are going to be brought into one of our four facilities. 
On the paste processing side, the tomatoes come in then they're sized and sorted. They move through the factory and at the simplest level, we are evaporating water out of tomato concentrate, or we are concentrating tomato juice to a customer's specification.

Our core business at [Company name] is to package tomato paste or diced tomatoes into 300 gallon bag-in-box bins or 55 gallon drums. We do retail sizes of canned products and food service sized products which mainly go into private label markets

California overall produces $95 \%$ of all the processed tomato products for the United States. Of that $95 \%$, [Company name] has $44 \%$ of the market share. [Company name] is doing almost half of the tomatoes processed for the U.S. markets.

Domestically if you were to go to a grocery store and walk in the frozen food section and look at the frozen pizzas we are in every one of those frozen pizzas in some degree, in every single one of those brands.

Because our market share is so substantial there is a $99 \%$ chance that in the last 5 days or within 5 days you would have eaten, or will eat, some of the tomatoes that you harvested. We are in virtually everything that you eat that involves tomato products and actually in fact a lot of products that might surprise you.

We ship to virtually every country that consumes tomato products so that's pretty much pick a country. The tomatoes you harvest will actually be shipped into Dubai, Turkey put into cans and sent to Iraq, Iran, Afghanistan - all huge consumers of tomato products. So people around the world are eating the tomatoes that you harvest around the world all day every day, year in year out.

Now Susan is going to be talking next about how she is impacted and the meaning it has for her. She is our customer, a representative of [Customer name].

I am Susan and I work for [Customer name] in sales, which means that I handle national accounts for the restaurant chains that we service. [Customer name] is a custom formulated tomato pouch company so what we do is only take care of our restaurant companies. I travel the country and handle customers such like Dominos, Pizza Hut, Taco Bell, Subway, and Little Caesar's; that is who [Customer name] sells to. I know everyone who is listening to this has eaten at one of those places at some point probably in the last month--I hope.

All of the tomatoes that [Customer name] purchases are from [Company name]. So every single tomato and every single tomato bin of tomato paste that we buy comes from you and we produce from those bins of paste to make final products for our customers. We are very thrilled with that and our customers tend to be very happy with that too.

It's really important to us when we come out to the tomato fields every year that we tell our customers that every single tomato that they buy from us comes from the tomato fields that you harvest and produce. The most interesting the number one thing that our customers talk about in 
the year--about how the tomato visit was that they like seeing the plants, but that the most important and memorable time is when they come out to the tomato fields, see the tomato harvesting and they talk about the color of the tomatoes, the abundance of the tomatoes, the efficiency of the tomato that [Company name] is able to produce, and how important that is to them because the quality of the tomatoes are paramount to our customers and our customers don't have a clue about harvesting a tomato so when they come out to see us in the summer and with us out to the tomato fields that you are harvesting they are amazed.

They love seeing the tomato plants and seeing the tomato under the plants--seeing how red they are! They always comment about how gorgeous the color is and when they taste the tomatoes they are blown away by how sweet they are. When they get a chance to ride a harvester or seeing the quantity of tomatoes that come by so quickly that is just amazing to them and they are so appreciative of the fact that there is so much detail that is put into making sure that the finished product that we make for them starts in the field.

It has to start in the field and they look at everything that you are doing for them as far as making sure that no foreign material is in the tomatoes that end up going in their pizza sauce because they are so passionate about quality and making sure that their customer will come back to their restaurants.

They always talk about of course the price of the tomatoes for that year. They cannot accept any price increases. As you may remember, Little Caesar's for 10 years has had a $\$ 5$ hot and ready pizza. Dominos and Pizza Hut are in the midst of pizza wars anywhere from $\$ 7$ to $\$ 10$. So they come back to us and say we can't pay more for the tomatoes--we can't pay more for the tomatoes! It's so important that the costing is the same year after year. So they love that you at [Company name] do all that you can to run as efficiently as you can for our customers so that our customers feel secure in knowing that we are trying to keep all the cost down and at same time they are not losing the quality that they demand. And that they have come to know that we will provide for them that the tomatoes that we provide and produce and what we can obtain from [Company name] so they are really appreciative of that.

I would just like to relay thanks to all the harvesting colleagues for all the hard work you are doing for our customers. I so appreciate it--we so appreciate it! We would not be able to purchase the tomatoes that we do if you did not do all the jobs you do. And our customers are so appreciative of being able to count on us because of [Company name] and the work that you do. They can count on us year after year that we can provide them with great quality products with great efficiency. I cannot thank you enough. I expect things to grow over the years and be able to purchase more tomatoes from [Company name] and that is because of all of you, so thank you very much. 


\section{Appendix B}

Example of letters used in our experimental manipulation, Study 2

Example of letter from external beneficiary

Dear [LAB NAME] research assistants,

My name is [FIRST NAME]. I am a fifth-year Ph.D. student at [NAME OF UNIVERSITY]. I study interpersonal trust and ethical decision-making. My main stream of research investigates the tension between honesty and benevolence. Many of our most common and difficult ethical dilemmas involve balancing honesty and benevolence. We routinely face this conflict in our personal lives, when deciding how to communicate with friends and family members, and in our professional lives, when deciding how to deliver difficult news and critical feedback. Using a variety of research methods, I study how individuals navigate this tension. I believe that my work on this topic will help individuals, scholars, and practitioners understand how to improve interpersonal communication and create ethical organizations.

I have been deeply influenced by the research produced at [NAME OF UNIVERSITY WHERE THE LAB IS], research that is made possible by your work, and the work of other research assistants like you. In particular, my research is heavily influenced by the findings of [ONE OF THE PROFESSORS IN THE LAB]—one of the researchers whose work the [LAB NAME] lab supports.

[ONE OF THE PROFESSORS IN THE LAB]'s work on ethical decision-making has inspired many young researchers like me. Not only has her research fundamentally changed the way we think about unethical behavior, but she has introduced many of the experimental paradigms that make it possible to study unethical behavior. Her research projects involve large volumes of data and hundreds of experiments. Running experiments is incredibly laborious - it takes a lot of time and effort to prepare materials, recruit participants, run the study, and make sense of the subsequent data. I know from my own experience that experiments cannot possibly be conducted well, and data cannot be coded and analyzed, without the help of focused and dedicated research assistants like you.

Please know that your hard work is sincerely appreciated. It makes impactful research possible. Because of the research that you helped produce, I have been able to produce my own research on ethical decision-making, which I hope will influence how individuals and organizations think about ethics and also inspire the next generation of academics.

So thank you - from me, and on behalf of all of the doctoral students, professors, and business leaders who will benefit from your work today and in the future!

Sincerely, [FIRST AND LAST NAME] [NAME OF UNIVERSITY] PhD Student 


\section{Example of letter from internal beneficiary}

Dear [LAB NAME] research assistants,

My name is [FIRST NAME] and I am in my third-year in the Ph.D. program at [NAME OF UNIVERSITY AND PROGRAM] studying judgment and decision-making. I am interested in how we perceive and judge others in decision-making roles and how our own decision-making is affected by our beliefs of how others will evaluate us. I believe my work will help individuals in a variety of different organizational contexts do a better job of making important decisions.

My research projects often involve thinking of creative ways to operationalize and design research experiments and thinking about how my research questions build upon but are different from past research. It is with the help of research assistants, like you, who are intelligent, curious, motivated, hardworking and creative, that I can move my research forward.

I recently worked with a research assistant like you who spent many hours spearheading a vast literature review on a novel question we believed had not been studied. This research assistant also helped me think outside the box and brainstormed with me about creative ways to design the laboratory study so that we could explore the questions we were interested in without deceiving any of the participants about what was taking place in the lab.

Thank you for all the work you have done and are doing as a research assistant. It is because of research assistants like you that I am able to be a productive researcher. Your work is not only helping me, but also contributing to the larger field of organizational behavior.

Thank you so much for being a [NAME OF UNIVERSITY] research assistant. The work you do is very important to us, as researchers, and all of us at [NAME OF UNIVERSITY] are so grateful to collaborate with you. Thank you again!

Sincerely,

[FIRST AND LAST NAME]

[NAME OF UNIVERSITY] PhD Student 


\section{References}

Aron, A., D. G. Dutton, E. N. Aron, and A. Iverson

1989 "Experiences of falling in love." Journal of Social and Personal Relationships, 6: 243257.

Aron, A., and T. McLaughlin-Volpe

2001 "Including others in the self: Extensions to own and partner's group memberships." Retrieved from http://psycnet.apa.org.ezp-prod1.hul.harvard.edu/psycinfo/2001-16359005

Aron, A., T. McLaughlin-Volpe, D. Mashek, G. Lewandowski, S. C. Wright, and E. N. Aron 2004 "Including others in the self." European Review of Social Psychology, 15: 101-132.

Ashforth, B. E., and F. Mael

1989 "Social identity theory and the organization." Academy of Management Review, 14: 20-39.

Baard, P. P., E. L. Deci, and R. M. Ryan

2004 "Intrinsic Need Satisfaction: A Motivational Basis of Performance and Weil-Being in Two Work Settings1." Journal of Applied Social Psychology, 34: 2045-2068.

Bartel, C. A., A. Wrzesniewski, B. Wiesenfeld, C. A. Bartel, S. Blader, and A. Wrzesniewski 2007 "The struggle to establish organizational membership and identification in remote work contexts." Identity and the Modern Organization, 119-133.

Bartel, C. A., A. Wrzesniewski, and B. M. Wiesenfeld 2012 "Knowing where you stand: Physical isolation, perceived respect, and organizational identification among virtual employees." Organization Science, 23: 743-757.

Batson, C. D., N. Ahmad, A. A. Powell, E. L. Stocks, J. Shah, and W. L. Gardner 2008 "Prosocial motivation." Handbook of Motivation Science, 135-149.

Batson, C. D., N. Ahmad, and E. L. Stocks

2011 "Four forms of prosocial motivation: Egoism, altruism, collectivism, and principlism." Social Motivation, 103-126.

Batson, C. D., and A. A. Powell

2003 "Altruism and prosocial behavior." Handbook of Psychology.

Baumeister, R. F., and M. R. Leary

1995 "The need to belong: desire for interpersonal attachments as a fundamental human motivation." Psychological Bulletin, 117: 497.

Buell, R. W., and M. I. Norton

2011 "The labor illusion: How operational transparency increases perceived value." Management Science, 57: 1564-1579. 
Burger, J. M., N. Messian, S. Patel, A. del Prado, and C. Anderson

2004 "What a coincidence! The effects of incidental similarity on compliance." Personality and Social Psychology Bulletin, 30: 35-43.

Cable, D. M., F. Gino, and B. R. Staats

2013 "Breaking them in or eliciting their best? Reframing socialization around

newcomers' authentic self-expression." Administrative Science Quarterly, 58: 1-36.

Clark, M. S., R. Oullette, M. C. Powell, and S. Milberg

1987 "Recipient's mood, relationship type, and helping." Journal of Personality and Social Psychology, 53: 94.

Deci, E. L., R. M. Ryan, M. Gagné, D. R. Leone, J. Usunov, and B. P. Kornazheva

2001 "Need satisfaction, motivation, and well-being in the work organizations of a former eastern bloc country: A cross-cultural study of self-determination." Personality and Social Psychology Bulletin, 27: 930-942.

Dutton, J., G. Debebe, and A. Wrzesniewski

1999 Being valued and devalued at work: a social valuing perspective'. Working paper, University of Michigan, Ann Arbor. Retrieved from

http://webuser.bus.umich.edu/janedut/High\%20Quality\%20Connections/Being\%20value d\%20\%20final.pdf

Dutton, J. E., and E. D. Heaphy

2003 "The power of high-quality connections." Positive Organizational Scholarship:

Foundations of a New Discipline, 3: 263-278.

Dutton, J. E., and B. R. E. Ragins

2007 "Exploring positive relationships at work: Building a theoretical and research foundation."

Ellemers, N., D. De Gilder, and S. A. Haslam

2004 "Motivating individuals and groups at work: A social identity perspective on

leadership and group performance." Academy of Management Review, 29: 459-478.

Gagné, M., and E. L. Deci

2005 "Self-determination theory and work motivation." Journal of Organizational

Behavior, 26: 331-362.

Gardner, W. L., S. Gabriel, and L. Hochschild

2002 "When you and I are' we,' you are not threatening: the role of self-expansion in social comparison." Journal of Personality and Social Psychology, 82: 239.

Gold, J. A., R. M. Ryckman, and N. R. Mosley 
1984 "Romantic Mood Induction and Attraction to a Dissimilar Other Is Love Blind?" Personality and Social Psychology Bulletin, 10: 358-368.

Grant, A. M.

2007 "Relational job design and the motivation to make a prosocial difference." Academy of Management Review, 32: 393-417.

2008 "The significance of task significance: Job performance effects, relational mechanisms, and boundary conditions." Journal of Applied Psychology, 93: 108.

2008 "Designing jobs to do good: Dimensions and psychological consequences of prosocial job characteristics." The Journal of Positive Psychology, 3: 19-39.

2008 "The significance of task significance: Job performance effects, relational mechanisms, and boundary conditions." Journal of Applied Psychology, 93: 108.

Grant, A. M., E. M. Campbell, G. Chen, K. Cottone, D. Lapedis, and K. Lee 2007 "Impact and the art of motivation maintenance: The effects of contact with beneficiaries on persistence behavior." Organizational Behavior and Human Decision Processes, 103: 53-67.

Grant, A. M., and F. Gino

2010 "A little thanks goes a long way: Explaining why gratitude expressions motivate prosocial behavior." Journal of Personality and Social Psychology, 98: 946.

Grant, A. M., and S. K. Parker

2009 "7 Redesigning Work Design Theories: The Rise of Relational and Proactive

Perspectives." The Academy of Management Annals, 3: 317-375.

Hackman, J. R., and G. R. Oldham

1976 "Motivation through the design of work: Test of a theory." Organizational Behavior and Human Performance, 16: 250-279.

1980 "Work redesign." Retrieved from

http://scholar.harvard.edu/rhackman/publications/work-redesign

Hale, E. E.

1918 The Man without a Country Vol. 1. Little, Brown.

Hoyle, R. H., and A. M. Crawford

1994 "Use of individual-level data to investigate group phenomena issues and strategies." Small Group Research, 25: 464-485.

Huber, P. J.

1967 "The behavior of maximum likelihood estimates under nonstandard conditions." Proceedings of the Fifth Berkeley Symposium on Mathematical Statistics and Probability Vol. 1: 221-233.

Ickes, W., and J. A. Simpson 
2008 "Motivational Aspects ofEmpathic Accuracy." Blackwell Handbook of Social Psychology: Interpersonal Processes, 2: 229.

Jiang, L., J. Hoegg, D. W. Dahl, and A. Chattopadhyay

2010 "The persuasive role of incidental similarity on attitudes and purchase intentions in a sales context." Journal of Consumer Research, 36: 778-791.

Jones, J. T., B. W. Pelham, M. Carvallo, and M. C. Mirenberg 2004 "How do I love thee? Let me count the Js: implicit egotism and interpersonal attraction." Journal of Personality and Social Psychology, 87: 665.

Keyes, C. L. M.

1998 "Social well-being." Social Psychology Quarterly, 121-140.

Latham, G. P., and C. C. Pinder

2005 "Work motivation theory and research at the dawn of the twenty-first century." Annu. Rev. Psychol., 56: 485-516.

Leary, M.

1995 Self-Presentation: Impression Management and Interpersonal Behavior. Brown \& Benchmark Publishers.

Leary, M., and A. Allen

2010 "Belonging motivation: Establishing, maintaining, and repairing relational value." Social Motivation, 37-56.

Leary, M. R., and C. B. Cox

2008 "Belongingness motivation: A mainspring of social action." Handbook of Motivation Science, 27-40.

Maslow, A.

1968 “Toward a psychology of being." New York: John.

McAdams, D. P., and E. D. de St Aubin

1992 "A theory of generativity and its assessment through self-report, behavioral acts, and narrative themes in autobiography." Journal of Personality and Social Psychology, 62: 1003.

McCullough, M. E., S. D. Kilpatrick, R. A. Emmons, and D. B. Larson

2001 "Is gratitude a moral affect?" Psychological Bulletin, 127: 249.

Miller, R. B., B. A. Greene, G. P. Montalvo, B. Ravindran, and J. D. Nichols 1996 "Engagement in academic work: The role of learning goals, future consequences, pleasing others, and perceived ability." Contemporary Educational Psychology, 21: 388422. 
Mitchell, T. R., and D. Daniels

2003 “Motivation." Handbook of Psychology. John Wiley \& Sons, Inc.

Morgeson, F. P., and M. A. Campion

2003 "Work design." Handbook of Psychology. Retrieved from

http://onlinelibrary.wiley.com/doi/10.1002/0471264385.wei1217/full

Morgeson, F. P., and S. E. Humphrey

2008 "Job and team design: Toward a more integrative conceptualization of work

design.” Research in Personnel and Human Resources Management, 27: 39-91.

O’Reilly, C. A., and J. Chatman

1986 "Organizational commitment and psychological attachment: The effects of compliance, identification, and internalization on prosocial behavior." Journal of Applied Psychology, 71: 492.

Pratt, M. G., and B. E. Ashforth

2003 "Fostering meaningfulness in working and at work." Positive Organizational

Scholarship: Foundations of a New Discipline, 309-327.

Reis, H. T.

2007 "Steps toward the ripening of relationship science." Personal Relationships, 14: 123.

Reis, H. T., M. S. Clark, and J. G. Holmes

2004 "Perceived partner responsiveness as an organizing construct in the study of intimacy and closeness." Handbook of Closeness and Intimacy, 201-225.

Salancik, G. R., and J. Pfeffer

1978 "A social information processing approach to job attitudes and task design." Administrative Science Quarterly, 224-253.

Shadish, W. R., T. D. Cook, and D. T. Campbell

2002 Experimental and Quasi-Experimental Designs for Generalized Causal Inference. Houghton, Mifflin and Company. Retrieved from http://psycnet.apa.org.ezpprod1.hul.harvard.edu/psycinfo/2002-17373-000

Shaver, P., and D. Buhrmester

1983 "Loneliness, sex-role orientation and group life: A social needs perspective." Basic Group Processes: 259-288. Springer.

Sherif, M., O. J. Harvey, B. J. White, W. R. Hood, C. W. Sherif, and others 1961 Intergroup Conflict and Cooperation: The Robbers Cave Experiment Vol. 10. University Book Exchange Norman, OK. 
Thornton, B., R. J. Audesse, R. M. Ryckman, and M. J. Burckle 2006 "Playing dumb and knowing it all: Two sides of an impression management coin." Individual Differences Research, 4.

Twenge, J. M., R. F. Baumeister, C. N. DeWall, N. J. Ciarocco, and J. M. Bartels 2007 "Social exclusion decreases prosocial behavior." Journal of Personality and Social Psychology, 92: 56.

Urdan, T., and M. Mestas

2006 "The goals behind performance goals." Journal of Educational Psychology, 98: 354.

Walton, G. M., and G. L. Cohen

2011 "Sharing motivation." Social Motivation, 79-101.

Walton, G. M., G. L. Cohen, D. Cwir, and S. J. Spencer

2012 "Mere belonging: the power of social connections." Journal of Personality and Social Psychology, 102: 513.

Weiss, R. S.

1973 "Loneliness: The experience of emotional and social isolation." Retrieved from http://psycnet.apa.org.ezp-prod1.hul.harvard.edu/psycinfo/1974-22306-000

White, $\mathrm{H}$.

1982 "Maximum likelihood estimation of misspecified models." Econometrica: Journal of the Econometric Society, 1-25.

Zalesny, M. D., and J. K. Ford

1990 "Extending the social information processing perspective: New links to attitudes, behaviors, and perceptions." Organizational Behavior and Human Decision Processes, 47: 205-246. 
Figures and Tables

Figure 1: Harvesting region (shaded)

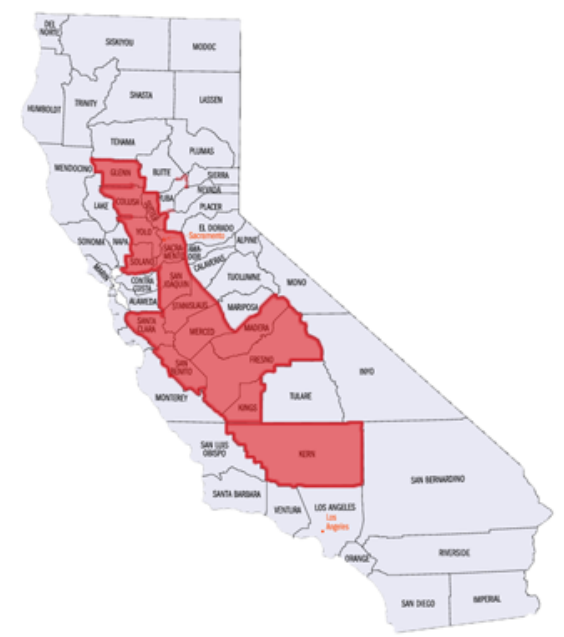

Table 1: Coefficients of OLS Regression of Tons Harvested Per Hour on Post-intervention and Internal and External Interactions, Days Elapsed Interactions and Controls, Study 1

\begin{tabular}{|c|c|c|c|}
\hline VARIABLES & $\begin{array}{c}\text { (1) } \\
\text { Differences in } \\
\text { Differences- } \\
\text { Controls Only }\end{array}$ & $\begin{array}{c}(2) \\
\text { Differences in } \\
\text { Differences } \\
\text { Estimates: Full } \\
\text { control group } \\
\end{array}$ & $\begin{array}{c}(3) \\
\text { Differences in } \\
\text { Differences } \\
\text { Estimates: Reduced } \\
\text { control group } \\
\end{array}$ \\
\hline Quality & $\begin{array}{c}79.53 * * * \\
(8.643)\end{array}$ & $\begin{array}{c}81.27 * * * \\
(8.614)\end{array}$ & $\begin{array}{c}101.4 * * * \\
(9.822)\end{array}$ \\
\hline Cumulative Tons Harvested & $\begin{array}{c}0.000879 * * * \\
(0.000107)\end{array}$ & $\begin{array}{c}0.000909 * * * \\
(0.000106)\end{array}$ & $\begin{array}{c}0.000834 * * * \\
(0.000128)\end{array}$ \\
\hline Cumulative Tons Squared & $\begin{array}{c}-3.09 \mathrm{e}-08 * * * \\
(3.87 \mathrm{e}-09)\end{array}$ & $\begin{array}{c}-3.06 \mathrm{e}-08 * * * \\
(3.70 \mathrm{e}-09)\end{array}$ & $\begin{array}{c}-2.69 \mathrm{e}-08 * * * \\
(4.29 \mathrm{e}-09)\end{array}$ \\
\hline Post-intervention & & $\begin{array}{c}-2.722 * * * \\
(0.562)\end{array}$ & $\begin{array}{c}-2.945 * * * \\
(0.686)\end{array}$ \\
\hline Post-intervention by Internal & & $\begin{array}{l}1.983 * * \\
(0.780)\end{array}$ & $\begin{array}{c}1.974 * * \\
(0.832)\end{array}$ \\
\hline Post-intervention by External & & $\begin{array}{c}0.305 \\
(0.705)\end{array}$ & $\begin{array}{c}0.310 \\
(0.724)\end{array}$ \\
\hline Night Shift Indicator & $\begin{array}{c}-1.388 \\
(1.175)\end{array}$ & $\begin{array}{l}-0.815 \\
(1.197)\end{array}$ & $\begin{array}{l}-1.256 \\
(1.296)\end{array}$ \\
\hline Consecutive Days Worked & $\begin{array}{c}0.172 * * * \\
(0.0514)\end{array}$ & $\begin{array}{c}0.168 * * * \\
(0.0506)\end{array}$ & $\begin{array}{l}0.172 * * * \\
(0.0584)\end{array}$ \\
\hline Percent of Shift Non-operating & $\begin{array}{c}-29.43 * * * \\
(0.771)\end{array}$ & $\begin{array}{c}-29.42 * * * \\
(0.772)\end{array}$ & $\begin{array}{c}-30.95 * * * \\
(0.860)\end{array}$ \\
\hline Ambient Temperature & $\begin{array}{c}0.0405 \\
(0.0265)\end{array}$ & $\begin{array}{l}-0.0184 \\
(0.0307)\end{array}$ & $\begin{array}{l}-0.0181 \\
(0.0318)\end{array}$ \\
\hline Constant & $\begin{array}{c}-55.85 * * * \\
(9.377)\end{array}$ & $\begin{array}{c}-53.60 * * * \\
(9.389)\end{array}$ & $\begin{array}{c}-72.67 * * * \\
(11.08)\end{array}$ \\
\hline $\begin{array}{l}\text { Observations } \\
\text { R-squared }\end{array}$ & $\begin{array}{l}7,818 \\
0.383\end{array}$ & $\begin{array}{l}7,818 \\
0.386\end{array}$ & $\begin{array}{l}5,582 \\
0,422\end{array}$ \\
\hline $\begin{array}{l}\text { Number of Employees } \\
\text { Grower Fixed Effects } \\
\text { Employee Fixed Effects } \\
\text { Internal=External }\end{array}$ & $\begin{array}{c}180 \\
\text { YES } \\
\text { YES }\end{array}$ & $\begin{array}{c}180 \\
\text { YES } \\
\text { YES } \\
\mathbf{0 . 0 6 8 5}\end{array}$ & $\begin{array}{c}100 \\
\text { YES } \\
\text { YES } \\
\mathbf{0 . 0 5 8 9}\end{array}$ \\
\hline
\end{tabular}

Robust standard errors in parentheses

$* * * \mathrm{p}<0.01, * * \mathrm{p}<0.05, * \mathrm{p}<0.1$ 
TABLE 2.

Summary statistics, Study 2.

\begin{tabular}{lccccc}
\hline Measure & Mean & $\begin{array}{c}\text { Standard } \\
\text { deviation }\end{array}$ & $\mathbf{1}$ & $\mathbf{2}$ & $\mathbf{3}$ \\
\hline 1. Sense of belongingness & 2.92 & 1.52 & 1 & & \\
$\begin{array}{l}\text { 2. Psychological } \\
\text { motivation }\end{array}$ & 4.59 & 1.36 & $.56^{* *}$ & 1 & \\
\begin{tabular}{l} 
3. Task performance \\
\hline
\end{tabular} & 23.04 & 7.57 & $.23^{* *}$ & $.15^{+}$ & 1 \\
\hline
\end{tabular}

Notes. ${ }^{*} p<.05,{ }^{* *} p<.01,{ }^{* * *} p<.001,{ }^{+} p<.10$

TABLE 3.

Summary statistics by condition, Study 2.

\begin{tabular}{cccc}
\hline Condition & $\begin{array}{c}\text { Sense of } \\
\text { Belongingness }\end{array}$ & $\begin{array}{c}\text { Psychological } \\
\text { Motivation }\end{array}$ & $\begin{array}{c}\text { Task } \\
\text { Performance }\end{array}$ \\
\hline Internal & 3.79 & 4.95 & 25.72 \\
Beneficiary & $(1.27)$ & $(1.23)$ & $(6.96)$ \\
Control & 2.04 & 4.42 & 22.19 \\
condition & $(1.13)$ & $(1.36)$ & $(7.24)$ \\
External & 2.97 & 4.42 & 21.36 \\
Beneficiary & $(1.61)$ & $(1.44)$ & $(7.90)$ \\
\hline
\end{tabular}

Note. Standard deviations are reported in parentheses. 